\title{
Gender-dependent effects of gonadectomy on lung carcinogenesis by 4-(methylnitrosamino)-1-(3-pyridyl)-1-butanone (NNK) in female and male $\mathrm{A} / \mathrm{J}$ mice
}

\author{
FUMIKO NINOMIYA, MASANAO YOKOHIRA, SOSUKE KISHI, YUKO NAKANO, KEIKO YAMAKAWA, \\ TATSUSHI INOUE, TOSHIYA KUNO and KATSUMI IMAIDA
}

Onco-Pathology, Department of Pathology and Host-Defense, Faculty of Medicine, Kagawa University, Miki-cho, Kita-gun, Kagawa 761-0793, Japan

Received August 12, 2013; Accepted September 13, 2013

DOI: $10.3892 /$ or.2013.2759

\begin{abstract}
The present study was conducted to investigate the effects of gonadectomy on lung carcinogenesis in female and male mice, and to determine an association between sex hormone and lung carcinogenesis. Female and male A/J mice were divided into gonadectomized and unoperated control groups and all animals were treated intraperitoneally with 1 or 2 injections of 4-(methylnitrosamino)-1-(3-pyridyl)-1butanone (NNK) at the dose of $2 \mathrm{mg} /$ mouse. The mice were sacrificed 18 or 56 weeks after surgery. Serum levels of estradiol in females and testosterone in males were confirmed to be decreased by gonadectomy. Lung white nodules were detected in all mice of all groups. In the control groups of 18- and 56-week studies, the multiplicities of lung nodules in females were significantly greater than in males. In males in the 56-week study, the multiplicity of macroscopical lung nodules, bronchiolo-alveolar hyperplasias, adenomas and tumors (adenomas and adenocarcinomas) showed significant increase with castration. In females in the 18-week study, the multiplicity of adenomas decreased significantly by ovariectomy. Based on the results of the present study, female A/J mice were confirmed to be more susceptible to NNK-induced lung carcinogenesis than males. Furthermore, it was suggested that the process is inhibited by testosterone and accelerated by estradiol. These findings indicate the possibility that sex hormones play important roles in determining sex differences in lung carcinogenesis in the $\mathrm{A} / \mathrm{J}$ mice initiated by NNK.
\end{abstract}

\section{Introduction}

Lung cancer prognosis remains very poor, with a 5-year survival rate generally $<20 \%$, lower than several other leading

Correspondence to: Professor Katsumi Imaida, Onco-Pathology, Department of Pathology and Host-Defense, Faculty of Medicine, Kagawa University, 1750-1 Ikenobe, Miki-cho, Kita-gun, Kagawa 761-0793, Japan E-mail: imaida@med.kagawa-u.ac.jp

Key words: lung tumorigenesis, gonadectomy, sex hormone, 4-(methylnitrosamino)-1-(3-pyridyl)-1-butanone, A/J mouse cancers, underlining the need for a better understanding of lung cancer formation and, ultimately, for identification of better therapeutic targets (1). Cigarette smoking is acknowledged to be the most important risk factor for human lung carcinogenesis and 4-(methylnitrosamino)-1-(3-pyridyl)-1butanone (NNK) is a tobacco-specific $\mathrm{N}$-nitrosamine which is considered to play important roles in tobacco-related human lung cancer $(2,3)$. NNK is also a strong lung carcinogen in rodents, inducing bronchiolo-alveolar hyperplasia, adenoma and adenocarcinoma (4). Previously, we demonstrated that $\mathrm{NNK}$-induced lung carcinogenesis in female $\mathrm{A} / \mathrm{J}$ mice was strongly inhibited by treatment with 8-methoxypsoralen, a potent human cytochrome P450 2A6 (CYP2A6) inhibitor, before a single intraperitoneal injection (i.p.) of NNK (5-9). We also reported carcinogenic mechanisms and modifying effects of other factors using NNK-induced lung cancer animal models (10-15).

In the mouse, it is well known that females are generally more sensitive to chemical lung carcinogenesis, such as that induced by NNK, than males (16). It is hypothesized that the difference is due to difference in the amount of sex hormones such as testosterone and estradiol. Also, in humans, the incidence of adenocarcinoma type lung cancer is known to be generally higher in women than in men (17-19). The available data suggest that gender and sex hormones affect the character of lung cancer $(20,21)$. For the purpose of these experiments, we hypothesized that the carcinogenesis of the lung may be influenced by sex hormone levels.

The present study was conducted to investigate effects of gonadectomy, ovariectomy and castration in female and male mice, respectively, on lung carcinogenesis and to determine associations with sex hormone levels, i.e. estradiol and testosterone. The experiments were conducted for 16 and 54 weeks after NNK treatment, since hyperplasia and adenoma lesions were earlier detected after 16 weeks (9), and adenocarcinomas were detected after 54 weeks (6).

\section{Materials and methods}

Chemicals. NNK was purchased from Toronto Research Chemicals (Toronto, Ontario, Canada). 
Table I. Body and relative organ weights.

\begin{tabular}{|c|c|c|c|c|c|c|c|c|}
\hline Group & Gender ${ }^{\mathrm{a}}$ & Treatment $^{\mathrm{a}}$ & Duration $^{\mathrm{b}}$ & No. ${ }^{c}$ & $\begin{array}{l}\text { Body weight }{ }^{\mathrm{d}} \\
\text { (g) }\end{array}$ & $\begin{array}{c}\text { Lung }^{\mathrm{d}} \\
\text { Relative }(\%)\end{array}$ & $\begin{array}{c}\text { Liver }^{\mathrm{d}} \\
\text { Relative }(\%)\end{array}$ & $\begin{array}{c}\text { Kidneys }^{\mathrm{d}} \\
\text { Relative }(\%)\end{array}$ \\
\hline 1 & $\mathrm{~F}$ & NNKx2 OVX & 18 & 21 & $24.81 \pm 2.80$ & $0.70 \pm 0.08$ & $4.50 \pm 0.26^{\mathrm{e}}$ & $1.10 \pm 0.10$ \\
\hline 2 & $\mathrm{~F}$ & $\mathrm{NNK} 2 \mathrm{~N}$ & 18 & 15 & $23.76 \pm 2.44$ & $0.70 \pm 0.08$ & $4.28 \pm 0.23$ & $1.13 \pm 0.07$ \\
\hline 3 & M & NNKx2 CAST & 18 & 16 & $26.50 \pm 2.67$ & $0.66 \pm 0.08$ & $4.22 \pm 0.18^{f}$ & $0.98 \pm 0.05^{\mathrm{g}}$ \\
\hline 4 & M & $\mathrm{NNK} 2 \mathrm{~N}$ & 18 & 15 & $27.96 \pm 2.20$ & $0.65 \pm 0.09$ & $4.61 \pm 0.22$ & $1.26 \pm 0.11$ \\
\hline 5 & $\mathrm{~F}$ & NNKx1 OVX & 56 & 18 & $31.04 \pm 4.07^{\mathrm{h}}$ & $1.23 \pm 0.53$ & $4.20 \pm 0.52$ & $1.57 \pm 2.08$ \\
\hline 6 & $\mathrm{~F}$ & NNKx1 N & 56 & 12 & $25.80 \pm 3.09$ & $1.27 \pm 0.23$ & $4.18 \pm 0.76$ & $1.19 \pm 0.27$ \\
\hline 7 & M & NNKx1 CAST & 56 & 21 & $33.19 \pm 4.17$ & $0.86 \pm 0.21$ & $3.67 \pm 0.23^{\mathrm{i}}$ & $0.80 \pm 0.09^{j}$ \\
\hline 8 & M & NNKx1 N & 56 & 14 & $30.33 \pm 4.41$ & $0.86 \pm 0.18$ & $4.28 \pm 0.40$ & $1.34 \pm 0.13$ \\
\hline
\end{tabular}

${ }^{\mathrm{a}} \mathrm{F}$, female; M, male; OVX, ovariectomy; CAST, castration; N, unoperated. ${ }^{\mathrm{b}}$ Weeks. ${ }^{\mathrm{c} N u m b e r}$ of mice examined. ${ }^{\mathrm{d}}$ Means \pm standard deviation.

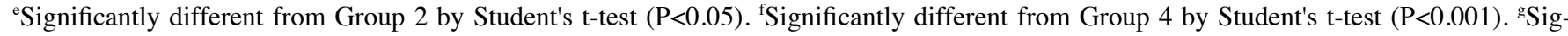

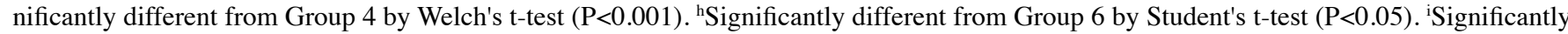
different from Group 8 by Welch's t-test $(\mathrm{P}<0.001)$. . Significantly different from Group 8 by Student's t-test $(\mathrm{P}<0.001)$.

Animals. A total of 72 female and 72 male A/J mice (5 weeks of age), purchased from Shizuoka Laboratory Animal Center (Shizuoka, Japan), were maintained in the Division of Animal Experiments, Life Science Research Center, Kagawa University, according to the Institutional Regulations for Animal Experiments. The regulations included the best considerations on animal welfare and good practice of animal handling contributing to the replacement, refinement and reduction of animal testing (3Rs). The protocols of the experiments were approved by the Animal Care and Use Committee for Kagawa University. All animals were housed in polycarbonate cages with white wood chips for bedding, and given free access to drinking water and a basal diet, Oriental MF (Oriental Yeast Co., Ltd., Tokyo, Japan), under controlled conditions of humidity $(60 \pm 10 \%)$, lighting (12 h light/dark cycle) and temperature $\left(24 \pm 2^{\circ} \mathrm{C}\right)$.

Experimental design. At 6 weeks of age, the mice were separated into 8 groups (Groups 1-8) of 15-21 animals each (Table I). Groups 1 and 5 were female groups undergoing ovariectomy. Groups 2 and 6 were females without ovariectomy. Groups 3 and 7 were male groups with castration, while Groups 4 and 8 were males without surgery. At the operations, the ovaries or the testes were removed under deep anesthesia (Groups 1, 3,5 and 7) with i.p. of $0.025 \mathrm{ml}$ pentobarbital sodium (Somunopentyl; Kyoritsu Seiyaku Co., Tokyo, Japan) diluted with $0.225 \mathrm{ml}$ saline (Otsuka isotonic sodium chloride solution; Otsuka Pharmaceutical Factory, Inc., Tokushima, Japan). The ovaries of female mice were resected from the retroperitoneum with a vertical incision in the back skin. The testes of male mice were resected from the center of the ventral scrota. The incision sites were closed with metal clips. At 2 weeks after surgery, all mice were treated with i.p. of NNK (2 mg/0.1 ml saline/mouse). After 3 weeks from surgery, Groups 1-4 were treated with another i.p. of NNK ( $2 \mathrm{mg} / 0.1 \mathrm{ml}$ saline/mouse). The experiment was terminated after 18 weeks for Groups 1-4 and after 56 weeks for Groups 5-8. All surviving mice were sacrificed under deep anesthesia. Blood samples were collected from the mice in Groups 1-4 to measure the serum concentrations of estradiol and testosterone. These hematological examinations were performed at SRL Inc. (Tokyo, Japan). The detection limit of the estradiol was $10 \mathrm{pg} / \mathrm{ml}$, and that of testosterone was $0.03 \mathrm{ng} / \mathrm{ml}$. Values lower than these limits were considered as 0 and means for each group were calculated. At autopsy, the lungs, livers and kidneys were removed. The lungs were weighed including trachea and heart first, infused with $10 \%$ neutral buffered formalin after separation from the trachea and heart, and then immersed in $10 \%$ neutral buffered formalin. Lung weights were finally calculated by subtraction of the weight of the remaining trachea and heart. These procedures are appropriate for accurate weighing and good tissue preservation. After fixation in formalin, all lungs were carefully inspected grossly using a stereomicroscope. All macroscopically detected lung nodules were counted and trimmed for histopathological evaluation. The livers and kidneys were weighed and immersed in $10 \%$ neutral buffered formalin. Slices of lungs, livers, kidneys and macroscopic mass lesions were routinely processed for embedding in paraffin for histopathological examination of hematoxylin and eosin stained sections.

Histopathological analysis. Each lung lobe of all mice was examined histopathologically. Lung proliferative lesions were diagnosed as bronchiolo-alveolar hyperplasia, adenoma or adenocarcinoma according to the criteria of 'International Classification of Rodent Tumors: The Mouse' (22).

Statistical analysis. The incidences of lung proliferative lesions (macroscopically and histopathologically) were analyzed by the Fischer's exact probability test. Body and organ weights were analyzed by the Student's t-test or the Welch's t-test between groups. Multiplicities of lung proliferative lesions (macroscopically and histopathologically) were analyzed by the Student's t-test or the Welch's t-test between groups. The Student's t-test was applied when equal variance was obtained and the Welch's t-test with unequal variance. 
Table II. Serum concentrations of estradiol and testosterone.

\begin{tabular}{|c|c|c|c|c|c|c|c|}
\hline \multirow[b]{2}{*}{ Group } & \multirow[b]{2}{*}{ Gender $^{\mathrm{a}}$} & \multirow[b]{2}{*}{ Treatment $^{\mathrm{a}}$} & \multirow[b]{2}{*}{ Duration $^{\mathrm{b}}$} & \multicolumn{2}{|c|}{ Estradiol } & \multicolumn{2}{|c|}{ Testosterone } \\
\hline & & & & No. ${ }^{c}$ & $(\mathrm{pg} / \mathrm{ml})^{\mathrm{d}}$ & No. & $(\mathrm{ng} / \mathrm{ml})^{\mathrm{d}}$ \\
\hline 1 & $\mathrm{~F}$ & NNKx2 OVX & 18 & 9 & $\mathrm{DL}^{\mathrm{e}}$ & 5 & $0.14 \pm 0.1$ \\
\hline 2 & $\mathrm{~F}$ & NNKx2 N & 18 & 9 & $19.7 \pm 6.9$ & 8 & DL \\
\hline 3 & M & NNKx2 CAST & 18 & 9 & DL & 5 & DL \\
\hline 4 & M & NNKx2 N & 18 & 12 & DL & 8 & $1.06 \pm 2.4$ \\
\hline
\end{tabular}

${ }^{\mathrm{a}} \mathrm{F}$, female; M, male; OVX, ovariectomy; CAST, castration; N, unoperated. ${ }^{\mathrm{b}}$ Weeks. ${ }^{\mathrm{c}}$ Number of mice examined. ${ }^{\mathrm{d}}$ Means \pm standard deviation. eDL, below the detection limit.

Table III. Incidences and multiplicities of macroscopical lung nodules.

\begin{tabular}{|c|c|c|c|c|c|c|}
\hline \multirow[b]{2}{*}{ Group } & \multirow[b]{2}{*}{ Gender $^{\mathrm{a}}$} & \multirow[b]{2}{*}{ Treatment $^{\mathrm{a}}$} & \multirow[b]{2}{*}{ Duration $^{\mathrm{b}}$} & \multirow[b]{2}{*}{ No. ${ }^{c}$} & \multicolumn{2}{|c|}{ Macroscopical nodule } \\
\hline & & & & & Incidence (\%) & Multiplicity \\
\hline 1 & $\mathrm{~F}$ & NNKx2 OVX & 18 & 21 & $21 / 21(100.0)$ & $17.2 \pm 8.4$ \\
\hline 2 & $\mathrm{~F}$ & NNKx2 N & 18 & 15 & $15 / 15(100.0)$ & $19.7 \pm 6.9^{\mathrm{e}}$ \\
\hline 3 & $\mathrm{M}$ & NNKx2 CAST & 18 & 16 & $16 / 16(100.0)$ & $14.3 \pm 6.2$ \\
\hline 4 & $\mathrm{M}$ & NNKx2 N & 18 & 15 & $15 / 15(100.0)$ & $12.2 \pm 5.7$ \\
\hline 5 & $\mathrm{~F}$ & NNKx1 OVX & 56 & 18 & 18/18 (100.0) & $18.2 \pm 7.6$ \\
\hline 6 & $\mathrm{~F}$ & NNKx1 N & 56 & 12 & $12 / 12(100.0)$ & $20.6 \pm 6.0^{f}$ \\
\hline 7 & M & NNKx 1 CAST & 56 & 19 & $19 / 19(100.0)$ & $12.1 \pm 4.6^{\mathrm{g}}$ \\
\hline 8 & $\mathrm{M}$ & NNKx1 N & 56 & 14 & $14 / 14(100.0)$ & $7.6 \pm 3.3$ \\
\hline
\end{tabular}

${ }^{\mathrm{a}} \mathrm{F}$, female; M, male; OVX, ovariectomy; CAST, castration; N, unoperated. ${ }^{b}$ Weeks. ${ }^{\mathrm{c} N u m b e r}$ of mice examined. ${ }^{\mathrm{d}}$ Means \pm standard deviation.

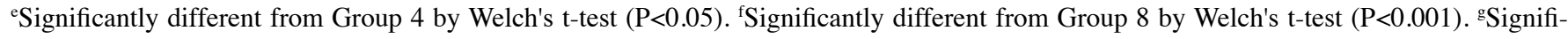
cantly different from Group 8 by Student's t-test $(\mathrm{P}<0.05)$.

\section{Results}

General conditions. One mouse from Group 3 died 3 weeks after castration. In Group 5, one mouse was sacrificed after 25 weeks from ovariectomy due to poor general condition and another died 54 weeks after ovariectomy. In Group 6, 2 mice were sacrificed 4 and 17 weeks after surgery due to poor general condition and another mouse died 54 weeks after surgery. In addition, one mouse of Group 8 died 53 weeks after surgery. All other mice demonstrated no marked change in their general condition.

Body and organ weights. Body and organ weights are shown in Table I. In the 18-week study (Groups 1-4), body weights exhibited no significant variation across groups. In the 56-week study (Groups 5-8), body weights in Group 5 (ovariectomy group) were significantly increased as compared with Group 6. Lung weights showed no significant differences between ovariectomy or castration groups and each unoperated group. Liver weights of Group 1 (ovariectomy group) were significantly increased as compared with Group 2, while liver and kidney weights of Group 3 and 7 (castration groups) were significantly decreased as compared with Groups 4 and 8, respectively.
Sex hormones in the blood samples. Serum concentrations of estradiol and testosterone in each group in the 18-week study (Groups 1-4) are shown in Table II. Blood samples with quantities sufficient for estradiol measurement were obtained from 12 mice of Group 4, and from 9 mice of Groups 1, 2 and 3. For testosterone measurement, 5 mice from Groups 1 and 3, and 8 mice from Groups 2 and 4 were used. In ovariectomized females (Group 1), the estradiol concentration decreased to below the detection limit while the concentration of testosterone was slightly increased compared to Group 2, but without statistical significance. In castrated male mice (Group 3), the concentration of testosterone decreased to below the detection limit compared to Group 4.

Macroscopical analysis. Macroscopically, lung white nodules were detected in all mice of all groups (Fig. 1). In Group 7 (56-week study), 2 mice were excluded from macroscopical and histopathological analysis due to the failure in fixation of lungs. Nodules in the 56-week study (Groups 5-8) were clearly larger than those observed after 18 weeks (Groups 1-4). Data for incidences and multiplicities of macroscopical lung nodules are summarized in Table III. The incidences were $100 \%$ in all groups. In unoperated groups, the multiplicities of lung nodules were significantly greater in females than in 


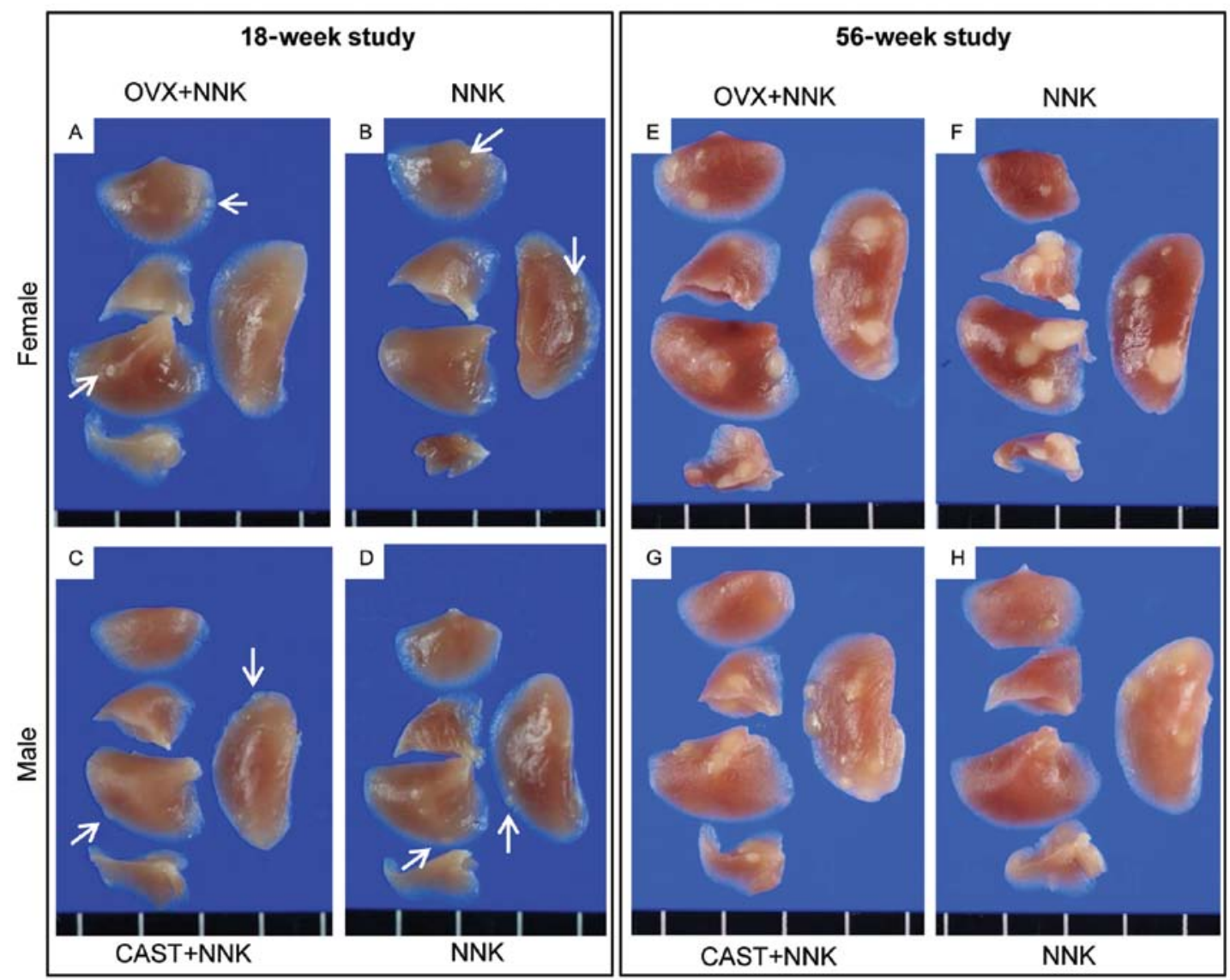

Figure 1. Macroscopical lung nodules. (A-D) In the 18-week study, small white nodules were observed in all groups (arrows indicate representative nodules in Groups 1-4). The sizes of the nodules observed in the 56-week study (E-H) were clearly larger than after 18 weeks (A-D). (A) Female ovariectomized group, Group 1; (B) female unoperated group, Group 2; (C) male castrated group, Group 3; (D) male unoperated group, Group 4; (E) female ovariectomized group, Group 5; (F) female unoperated group, Group 6; (G) male castrated group, Group 7; (H) male unoperated group, Group 8. OVX, ovariectomy; CAST, castration.

males of both 18 - and 56-week studies. In the 56-week study, the multiplicity of lung nodules in the male castrated group (Group 7) was significantly increased as compared to the male unoperated group (Group 8).

Histopathological analysis. In histopathological analysis of lung proliferative lesions, bronchiolo-alveolar hyperplasias and adenomas were observed in the 18-week study (Groups 1-4) and bronchiolo-alveolar hyperplasias, adenomas and adenocarcinomas after 56 weeks (Groups 5-8) (Fig. 2). Incidences and multiplicities of each proliferative lesion are summarized in Table IV. The incidences showed no significant intergroup variation in either 18- or 56-week studies. In the 18-week study, the multiplicity of adenomas in the female ovariectomized group (Group 1) was significantly lower than in the female unoperated group (Group 2). In the 56-week study, the multiplicities of hyperplasias, adenomas and tumors (adenomas and adenocarcinomas) in the male castrated group (Group 7) were significantly increased, and carcinomas showed a tendency to increase, compared with the male unoperated group (Group 8). In liver, a hepatocellular carcinoma was observed in only one case of Group 5. No other lesions were observed in liver histopathologically. There were no lesions detected in kidneys in any of the groups. A lipoma surrounding the kidney and a thymoma were observed in Group 5, each at incidences of $1 / 18(6 \%)$. No other tumors were observed in any of the groups.

\section{Discussion}

In the present 18 -week study, the serum concentration of estradiol of female mice was significantly decreased by ovariectomy, while the concentration of testosterone was slightly increased, and the serum concentration of testosterone of male mice was significantly decreased by castration. Estradiol is one of the most important sex steroid hormones secreted by the ovary and testosterone is a principal androgen secreted by the testis $(23,24)$. The decrease with gonadectomy was in line with expectation and the increase in testosterone in ovariectomized females may be due to the secretion by the adrenal cortex. It is known that steroid sex hormones, particularly androgen, are also secreted from adrenal cortex (25), and secretion may be augmented in ovariectomized female mice as a reaction to ovariectomy (26). However, the concentration of testosterone in ovariectomized female mice was much lower than that in unoperated males.

In males, body weights showed no significant difference with castration after both 18 and 56 weeks. In females of the 56-week study, body weights in the operated group (Group 5) were significantly increased and this seemed to be due to the ovariectomy. In ovariectomized female mice, increase of body fat, reduction of lipid metabolism and activation of lipid synthesis have been reported (27-29). In males of the 18- and 56-week studies, the liver and kidney weights of 


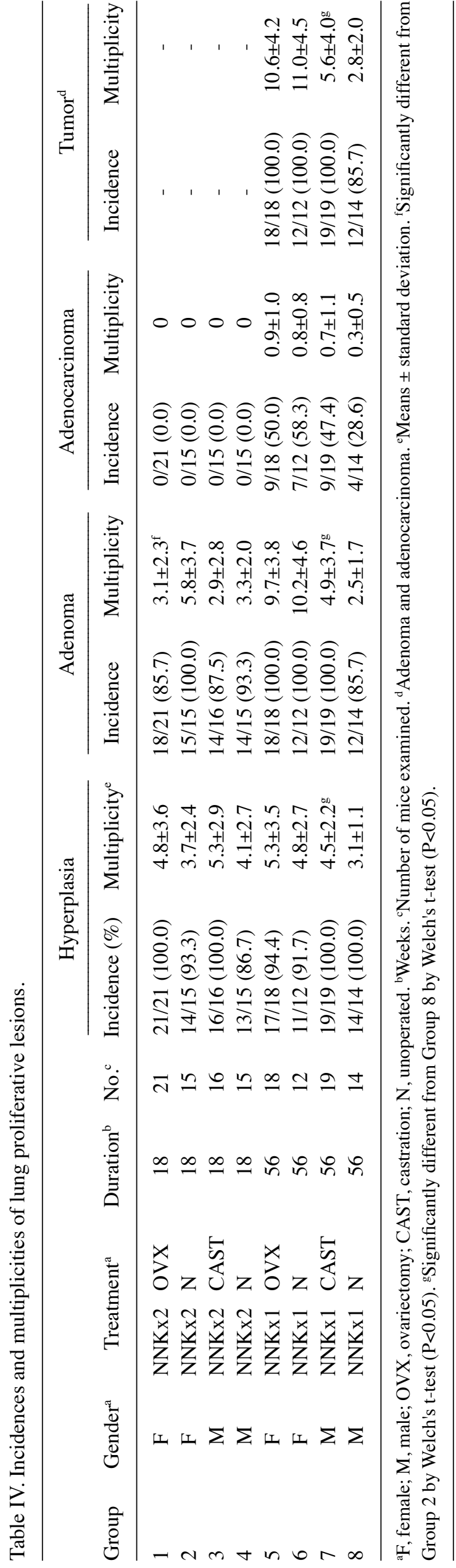

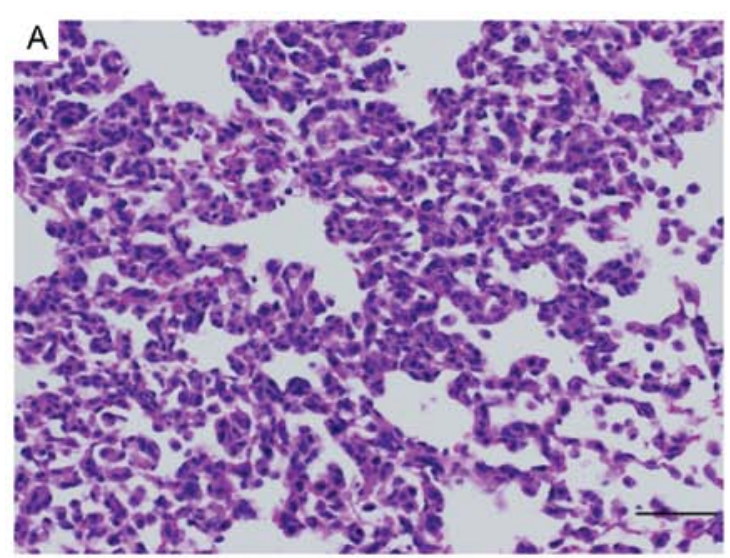
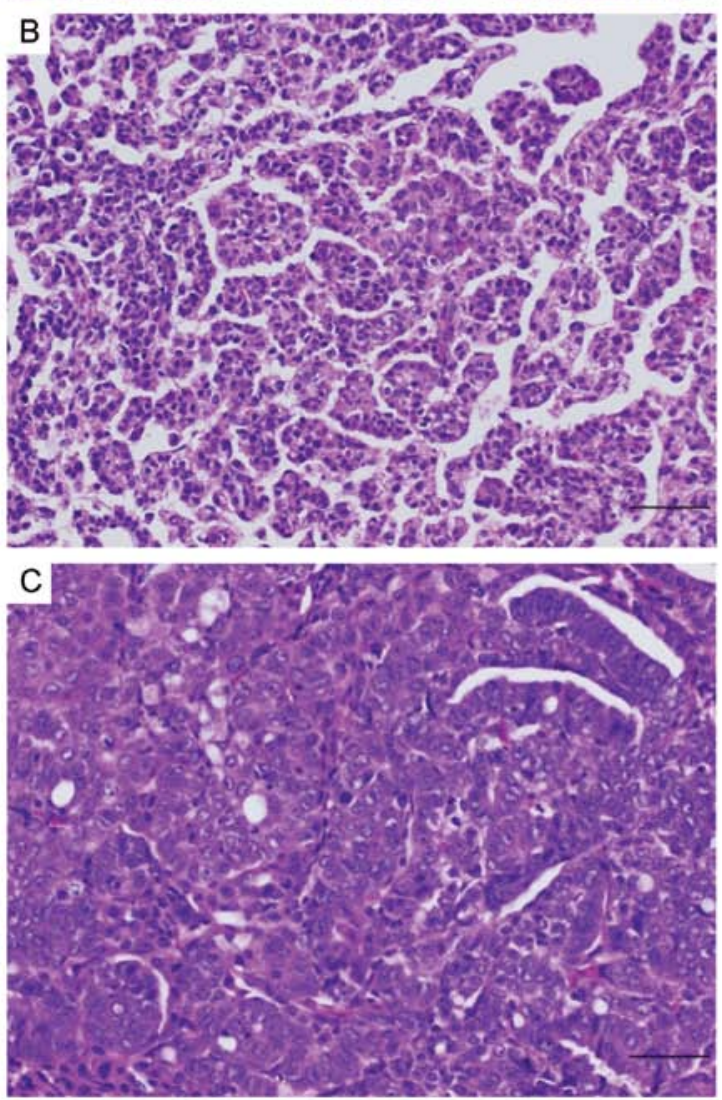

Figure 2. Histopathological lung proliferative lesions. Representative histopathology of lung lesions in the 56-week study. Bar, $50 \mu \mathrm{m}$. (A) Bronchioloalveolar hyperplasia in a Group-7 mouse; (B) adenoma in a Group-6 mouse; (C) adenocarcinoma in a Group-5 mouse.

castrated groups (Groups 3 and 7) were significantly decreased compared with the unoperated groups (Groups 4 and 8), and this may be due to the castration, as similar weight loss has been reported in castrated CF-1 mice (30). In females in the 18 -week study, the liver weight of the ovariectomized group (Group 1) showed significant increase compared with the unoperated group (Group 2), although no such difference was noted after 56 weeks. As there is no report to support this, the liver weights may be influenced by estradiol derived from the ovary.

In unoperated groups, the multiplicities of lung nodules in females (Groups 2 and 6) were significantly greater than in males (Groups 4 and 8), confirming female $\mathrm{A} / \mathrm{J}$ mice to be more susceptible to NNK-induced lung carcinogenesis 
than males. Our results indicated that lung carcinogenesis was increased by castration, suggesting the possibility that testosterone inhibits NNK-induced lung carcinogenesis. In addition, the results of the 18 -week study suggest that female sex hormones contribute to the malignant transformation of lung proliferative lesions, such as tumorous alteration from hyperplasia to adenoma. However, the results of the 56-week study did not support this suggestion.

In humans, there have been several reports that sex hormones affect incidences of lung adenocarcinoma. The characteristics of gene mutations in lung cancer are reported to differ between the sexes. In human lung cancer, tobaccorelated p53 and EGFR mutations are more common in women than in men (20). Thus, there is a possibility that lung carcinogenesis progresses through different pathways between men and women. Estradiol influences the activity of various metabolic enzymes, such as CYP2A6, CYP1A2, CYP3A4, CYP2C19, UDP-glucuronyltransferase, which can activate NNK to ultimate carcinogenic species $(2,31,32)$. In women, nicotine metabolism by CYP2A6 is reported to be accelerated by estrogen (33). Previously, we demonstrated that CYP2A6 plays important roles in NNK-induced lung carcinogenesis (5-9). In addition, oral contraceptives (estrogen) increase drug metabolism by glucuronidation (34-36). However, there are also reports that oral contraceptives decelerate drug metabolism by CYP1A2, CYP3A4 and CYP2C19 (37-39). Whatever the case, it appears clear that metabolic enzymes of NNK are influenced by estradiol. There is also the possibility that androgen influences lung carcinogenesis. Androgen receptors are present in human lung adenocarcinomas and normal lung tissue of humans and mice, and their expression in normal lung tissue of mice may be affected by castration and testosterone administration (40).

In male mice of the present study, tumors (adenomas and adenocarcinomas) were significantly increased in the castrated group only after 56 weeks, indicating that it is necessary to use long-term experiments in order to determine modifying potential of male sex hormones on lung carcinogenesis. The present study, in fact, pointed to the possibility that NNK-induced lung carcinogenesis may be inhibited by testosterone and accelerated by estradiol, although the effect was only slight in females. One explanation is that lung carcinogenic effects of NNK are so strong in females, that modifying effects of estradiol are masked.

In conclusion, female $\mathrm{A} / \mathrm{J}$ mice were confirmed to be more susceptible to NNK-induced lung carcinogenesis than males. In males, lung carcinogenesis was increased by castration, whereas in females, malignant transformation of lung proliferative lesions tended to be inhibited by ovariectomy. These results suggested that NNK-induced lung carcinogenesis is inhibited by testosterone and accelerated by estradiol. These findings indicate the possibility that sex hormones play important roles in determining sex differences in lung carcinogenesis in $\mathrm{A} / \mathrm{J}$ mice initiated by $\mathrm{NNK}$. Additional experiments are ongoing to confirm the effects of the sex hormones themselves.

\section{Acknowledgements}

We thank Dr Malcolm A. Moore for his help in the critical reading of this manuscript.

\section{References}

1. Balbo S, Upadhyaya P, Villalta PW, Qian X and Kassie F: DNA adducts in aldehyde dehydrogenase-positive lung stem cells of $\mathrm{A} / \mathrm{J}$ mice treated with the tobacco specific lung carcinogen 4-(methylnitrosamino)-1-(3-pyridyl)-1-butanone (NNK). Chem Res Toxicol: Mar 12, 2013 (Epub ahead of print).

2. Akopyan G and Bonavida B: Understanding tobacco smoke carcinogen NNK and lung tumorigenesis (Review). Int J Oncol 29: 745-752, 2006.

3. Chen RJ, Chang LW, Lin P and Wang YJ: Epigenetic effects and molecular mechanisms of tumorigenesis induced by cigarette smoke: an overview. J Oncol 2011: 654931, 2011.

4. Belinsky SA, Devereux TR, Foley JF, Maronpot RR and Anderson MW: Role of the alveolar type II cell in the development and progression of pulmonary tumors induced by 4-(methylnitrosamino)-1-(3-pyridyl)-1-butanone in the A/J mouse. Cancer Res 52: 3164-3173, 1992.

5. Imaida K, Yokohira M and Kuno T: Detection of carcinogenic and modifying potentials by test compounds using a mouse lung carcinogenesis bioassay (Review). J Toxicol Pathol 20: 117-123, 2007.

6. Takeuchi H, Saoo K, Matsuda Y, et al: 8-Methoxypsoralen, a potent human CYP2A6 inhibitor, inhibits lung adenocarcinoma development induced by 4-(methylnitrosamino)-1-(3-pyridyl)-1butanone in female A/J mice. Mol Med Rep 2: 585-588, 2009.

7. Takeuchi H, Saoo K, Matsuda Y, et al: Dose dependent inhibitory effects of dietary 8-methoxypsoralen on NNK-induced lung tumorigenesis in female A/J mice. Cancer Lett 234: 232-238, 2006.

8. Takeuchi H, Saoo K, Yokohira M, et al: Pretreatment with 8-methoxypsoralen, a potent human CYP2A6 inhibitor, strongly inhibits lung tumorigenesis induced by 4-(methylnitrosamino)1-(3-pyridyl)-1-butanone in female A/J mice. Cancer Res 63: 7581-7583, 2003.

9. Yokohira M, Takeuchi H, Saoo K, et al: Establishment of a bioassay model for lung cancer chemoprevention initiated with 4-(methylnitrosamino)-1-(3-pyridyl)-1-butanone (NNK) in female A/J mice. Exp Toxicol Pathol 60: 469-473, 2008.

10. Kuno T, Yokohira M, Matsuda Y, et al: Lack of modifying potential of 8-methoxypsoralen in the promotion or progression stages of lung carcinogenesis in A/J female mice. Oncol Rep 20: 767-772, 2008.

11. Matsuda Y, Saoo K, Hosokawa K, et al: Post-initiation chemopreventive effects of dietary bovine lactoferrin on 4-(methylnitrosamino)-1-(3-pyridyl)-1-butanone-induced lung tumorigenesis in female A/J mice. Cancer Lett 246: 41-46, 2007.

12. Yamakawa K, Kuno T, Hashimoto N, et al: Molecular analysis of carcinogen-induced rodent lung tumors: Involvement of microRNA expression and Kras or Egfr mutations. Mol Med Rep 3: 141-147, 2010.

13. Yokohira M, Hashimoto N, Yamakawa K, Saoo K, Kuno T and Imaida K: Lack of promoting effects from physical pulmonary collapse in a female $\mathrm{A} / \mathrm{J}$ mouse lung tumor initiated with 4-(methylnitrosamino)-1-(3-pyridyl)-1-butanone (NNK) with remarkable mesothelial cell reactions in the thoracic cavity by the polymer. Exp Toxicol Pathol 63: 181-185, 2011.

14. Yokohira M, Hashimoto N, Yamakawa K, et al: Lack of modifying effects of intratracheal instillation of quartz or dextran sulfate sodium (DSS) in drinking water on lung tumor development initiated with 4-(Methylnitrosamino)-1-(3-pyridyl)-1-butanone (NNK) in female A/J mice. J Toxicol Pathol 22: 179-185, 2009.

15. Miyazaki M, Yamazaki $\mathrm{H}$, Takeuchi $\mathrm{H}$, et al: Mechanisms of chemopreventive effects of 8-methoxypsoralen against 4-(methylnitrosamino)-1-(3-pyridyl)-1-butanone-induced mouse lung adenomas. Carcinogenesis 26: 1947-1955, 2005.

16. Igarashi M, Watanabe M, Yoshida M, et al: Enhancement of lung carcinogenesis initiated with 4-( $N$-hydroxymethylnitrosamino)1-(3-pyridyl)-1-butanone by Ogg1 gene deficiency in female, but not male, mice. J Toxicol Sci 34: 163-174, 2009.

17. Morita T: A statistical study of lung cancer in the annual of pathological autopsy cases in Japan, from 1958 to 1997, with reference to time trends of lung cancer in the world. Jpn J Cancer Res 93: 15-23, 2002.

18. Sobue T, Ajiki W, Tsukuma H, Oshima A, Hanai A and Fujimoto I: Trends of lung cancer incidence by histologic type: a populationbased study in Osaka, Japan. Jpn J Cancer Res 90: 6-15, 1999.

19. Zang EA and Wynder EL: Differences in lung cancer risk between men and women: examination of the evidence. J Natl Cancer Inst 88: 183-192, 1996. 
20. Belani CP, Marts S, Schiller J and Socinski MA: Women and lung cancer: epidemiology, tumor biology, and emerging trends in clinical research. Lung Cancer 55: 15-23, 2007.

21. Nishio M, Ohyanagi F, Horiike A, et al: Gefitinib treatment affects androgen levels in non-small-cell lung cancer patients. Br J Cancer 92: 1877-1880, 2005.

22. Mohr U (ed): International Classification of Rodent Tumors: The Mouse. 1st edition. Springer-Verlag, Berlin, 2001.

23. de Kretser DM: The Testis. In: Reproduction in Mammals: Hormonal Control of Reproduction. Austin CR and Short RV (eds). Vol 3.2nd edition. Cambridge University Press, Cambridge, pp76-90, 1984.

24. Baird DT: The Ovary. In: Reproduction in Mammals: Hormonal Control of Reproduction. Austin CR and Short RV (eds). Vol 3. 2nd edition. Cambridge University Press, Cambridge, pp91-114, 1984.

25. Pelletier G, Luu-The V, Li S and Labrie F: Localization of type 5 $17 \beta$-hydroxysteroid dehydrogenase mRNA in mouse tissues as studied by in situ hybridization. Cell Tissue Res 320: 393-398, 2005.

26. Matsuura S and Suzuki K: Morphological changes in the submandibular glands and in the $\mathrm{X}$ zone of the adrenal gland following ovariectomy in mice. Cell Tissue Res 246: 549-556, 1986.

27. Kamei Y, Suzuki M, Miyazaki H, et al: Ovariectomy in mice decreases lipid metabolism-related gene expression in adipose tissue and skeletal muscle with increased body fat. J Nutr Sci Vitaminol 51: 110-117, 2005.

28. Wu J, Wang X, Chiba H, et al: Combined intervention of soy isoflavone and moderate exercise prevents body fat elevation and bone loss in ovariectomized mice. Metabolism 53: 942-948, 2004.

29. Yamaguchi M, Katoh S, Morimoto C, et al: The hormonal responses of lipoprotein lipase activity and lipolysis in adipose tissue differ depending on the stage of the estrous cycle in female rats. Int J Obes Relat Metab Disord 26: 610-617, 2002.

30. Duffel MW, Graham JM and Ziegler DM: Changes in dimethylaniline N-oxidase activity of mouse liver and kidney induced by steroid sex hormones. Mol Pharmacol 19: 134-139, 1981.

31. Kamataki T, Fujita KI, Nakayama K, Yamazaki Y, Miyamoto M and Ariyoshi N: Role of human cytochrome P450 (CYP) in the metabolic activation of nitrosamine derivatives: application of genetically engineered Salmonella expressing human CYP. Drug Metab Rev 34: 667-676, 2002.
32. Wiener D, Doerge DR, Fang JL, Upadhyaya P and Lazarus P: Characterization of $\mathrm{N}$-glucuronidation of the lung carcinogen 4-(methylnitrosamino)-1-(3-pyridyl)-1-butanol (NNAL) in human liver: importance of UDP-glucuronosyltransferase 1A4. Drug Metab Dispos 32: 72-79, 2004.

33. Benowitz NL, Lessov-Schlaggar CN, Swan GE and Jacob P III: Female sex and oral contraceptive use accelerate nicotine metabolism. Clinl Pharmacol Ther 79: 480-488, 2006.

34. Miners JO, Grgurinovich N, Whitehead AG, Robson RA and Birkett DJ: Influence of gender and oral contraceptive steroids on the metabolism of salicytic acid and acetylsalicylic acid. Br J Clin Pharmacol 22: 135-142, 1986.

35. Mitchell MC, Hanew T, Meredith CG and Schenker S: Effects of oral contraceptive steroids on acetaminophen metabolism and elimination. Clin Pharmacol Ther 34: 48-53, 1983.

36. Stoehr GP, Kroboth PD, Juhl RP, Wender DB, Phillips JP and Smith RB: Effect of oral contraceptives on triazolam, temazepam, alprazolam, and lorazepam kinetics. Clin Pharmacol Ther 36: 683-690, 1984.

37. Balogh A, Klinger G, Henschel L, Börner A, Vollanth R and Kuhnz W: Influence of ethinylestradiol-containing combination oral contraceptives with gestodene or levonorgestrel on caffeine elimination. Eur J Clin Pharmacol 48: 161-166, 1995.

38. Laine K, Tybring G and Bertilsson L: No sex-related differences but significant inhibition by oral contraceptives of CYP2C19 activity as measured by the probe drugs mephenytoin and omeprazole in healthy Swedish white subjects. Clin Pharmacol Ther 68: 151-159, 2000.

39. Slayter KL, Ludwig EA, Lew KH, Middleton E Jr, Ferry JJ and Jusko WJ: Oral contraceptive effects on methylprednisolone pharmacokinetics and pharmacodynamics. Clin Pharmacol Ther 59: 312-321, 1996.

40. Mikkonen L, Pihlajamaa P, Sahu B, Zhang FP and Jänne OA: Androgen receptor and androgen-dependent gene expression in lung. Mol Cell Endocrinol 317: 14-24, 2010. 